\title{
Wind Tunnel Studies of Temperature Dependence and Behavior of Butterflies in the Context of Habitat Edges
}

\section{Authors: J. Rhea S. Waldman and Diane M. Debinski}

This is a postprint of an article that originally appeared in Journal of the Lepidopterists' Society February 2015. The final version can be found at https://doi.org/10.18473/lepi.69i2.a13.

Waldman, Rhea and Diane M. Debinski. 2015. Wind tunnel studies of temperature dependence and behavior of butterflies in the context of habitat edges. Journal of the Lepidopterists' Society. 69(2): 125-130. 


\title{
WIND TUNNEL STUDIES OF TEMPERATURE DEPENDENCE AND BEHAVIOR OF BUTTERFLIES IN THE CONTEXT OF HABITAT EDGES
}

\author{
J. Rhea S. Waldman* and Diane M. Debinski \\ Department of Ecology, Evolution and Organismal Biology, Iowa State University, Ames, IA 50011, USA \\ " previously published as R. von Busse, email: vonbusse@iastate.edu
}

\begin{abstract}
Wind tunnel studies provide a valuable experimental approach that can be used to investigate the influence of specific environmental parameters and to make generalizations about insect behavior. In this study, we designed an experiment to test the sensitivity of butterflies to isolated environmental parameters in the context of understanding edge responses. We tested the behavior of 21 different butterfly species in response to certain stimuli, including food source, feeder color, temperature, and UV light. Certain butterfly species (e.g. Heliconius melpomene and Papilio polytes) were particularly active in the wind tunnel setup. All butterfly species tested preferred blue feeders over white, yellow or pink. Investigation of the UV content of the different feeders and the butterflies' preferred nectar plant showed a similar wavelength response, which could indicate a UV preference in butterflies. We also observed species-dependent temperature preferences. Papilio lowii had a significant preference for the warm side $\left(36.0^{\circ} \mathrm{C}\right)$ of the wind tunnel, whereas Papilio polytes showed a significant preference for the cold side $\left(25.3^{\circ} \mathrm{C}\right)$.
\end{abstract}

Additional key words: flight, training, UV, perception, experiments

Wind tunnel studies have long been used to investigate animal flight (e.g. Pennycuick 1968, Tucker 1968). The biggest advantage of wind tunnel use is the ability to simplify a complex natural environment and allow for controllable and repeatable measurements. To ensure non-biased results of a lab or wind tunnel study, the experimental design needs to be adjusted carefully to represent conditions pertinent to the research question. Previous training and behavioral testing of the study species or individual can be essential for the success of the experiment (e.g. Pennycuick 1968). However, training butterflies presents a different set of challenges than training vertebrates, like birds or bats, and the butterflies' perception and learning capabilities need to be taken into account. Current studies by van Dyck (e.g., 2011) acknowledge a species' perception of its environment and highlight the importance of incorporating this species-specific perception when applying research questions to natural environments.

Our study was designed to investigate the sensitivity of butterflies to environmental parameters in the context of edge responses. Current habitat restorations aim to restore the function of original ecosystems and one measure of restoration success is the composition of the insect community. Butterflies are particularly good indicators because they are easily identifiable and are associated with the plant community both as herbivores and pollinators (e.g., Kremen 1992, Brown \& Freitas 2000, Shepherd \& Debinski 2005). However, some grassland butterfly species react strongly to the presence of habitat edges and show differential probabilities for crossing edges between different land cover types (e.g., road, treeline, field, or crop) (Ries \& Debinski 2001). The landscape today in most parts of the developed world is highly fragmented and these behavioral responses to edges could influence the dispersal and recolonization of restored habitats by butterfly species, thereby affecting the function of the restored ecosystem.

The conceptual model driving our wind tunnel experiment combines free flight in the context of a simplified environment to allow assessment of choice. By allowing the butterflies to fly freely in a confined space, an opportunity is provided for the researcher to evaluate selection for or against a particular environmental variable. The wind tunnel test section is divided into two parts, with one environmental parameter (e.g., temperature) varying across the two parts of the wind tunnel. An identical food source in each compartment is provided and the butterflies' preference is observed, recorded, and analyzed. Certain prerequisites, however, need to be achieved to promote the success of the experiments. The butterflies need to be acclimatized to the wind tunnel conditions and be willing to fly around the wind tunnel and feed from the offered food source. This involves prior training of the butterflies and appropriate environmental conditions to keep the butterflies active. To ensure the validity of the experiment, it is further necessary that the two compartments of the wind tunnel are identical except for the parameter to be tested. For example, if the test involves an artificial food source, the two sides of the chamber should not vary in smell, food quality, amount, etc. Here we present preliminary results with a focus on developing an experimental protocol that will provide a basis for future butterfly behavioral research using wind tunnels.

\section{Materials AND Methods}

Butterfly species. Table 1 provides an overview of the 21 butterfly species tested in the wind tunnel. The 
butterflies were supplied from the butterfly house of the Reiman Gardens at Iowa State University, where they were reared from caterpillars. All caterpillars were obtained from commercial butterfly farms and were most likely reared in captivity for several generations. Butterflies taken straight out of the rearing chamber where they had recently emerged were generally inactive for about $24 \mathrm{~h}$. Active butterflies caught in the butterfly house needed a couple of hours to adjust to wind tunnel conditions. The most success (i.e., the most activity) was attained by keeping individuals in the wind tunnel for several consecutive days. The tested species were selected depending on availability at the Reiman Gardens and encompassed a broad variety of both native and foreign species, different body and wing sizes, as well as fast and slow flying species. This allowed us to assess a wide variety of potential behavioral differences within the wind tunnel. The butterfly behavior is summarized in Table 1 and an assessment of the suitability of the species for these kinds of wind tunnel experiments is described. Two species, Heliconius melpomene and Papilio polytes, were by far the most active and displayed the desired feeding behavior. All other tested longwings showed similar activity levels and behavior, indicating a general suitability of this genus for wind tunnel experiments. Even by keeping individuals in the wind tunnel for several days and showing them the food source (extending the proboscis into the artificial nectar), some species did not accept the artificial food source or were not active and stayed in one spot.

TABLE 1: Butterfly species tested in the wind tunnel. The number of total individuals tested in the wind tunnel includes both the individuals that were only tested for a single day and the individuals that were used for repeated tests. The number of individuals that were used for repeated tests is displayed in a separate column with the number of days they spent in the wind tunnel in brackets.

\begin{tabular}{|c|c|c|c|c|}
\hline Species & \# total individuals & $\begin{array}{r}\text { \# individuals } \\
\text { (repeated tests) }\end{array}$ & Performance & Suitability \\
\hline Athyma perius & 2 & & sit mostly & more tests needed \\
\hline Battus philenor & 1 & & moderately active & possibly \\
\hline Cethosia cyane & 2 & & $\begin{array}{l}\text { mostly sits } \\
\text { nectars sitting }\end{array}$ & more tests needed \\
\hline Graphium agamemnon & 7 & $6(3)$ & sit mostly & no \\
\hline Heliconius charitonius & 5 & & moderately active & possibly \\
\hline Heliconius doris & 2 & $2(4)$ & active & possibly \\
\hline Heliconius melpomene & 11 & $5(5)$ & $\begin{array}{r}\text { very active } \\
\text { nectars sitting }\end{array}$ & yes \\
\hline Heliconius numata & 1 & $1(5)$ & active & possibly \\
\hline Hypolimnas bolina & 2 & & sit mostly & no \\
\hline Idea leuconoe & 10 & & $\begin{array}{c}\text { slow flight } \\
\text { nectars sitting }\end{array}$ & possibly \\
\hline Junonia coenia & 5 & $5(3)$ & $\begin{array}{c}\text { sit mostly } \\
\text { do not accept feeder }\end{array}$ & no \\
\hline Morpho peleides & 2 & & $\begin{array}{c}\text { sit mostly } \\
\text { feeds on rotten fruit }\end{array}$ & no \\
\hline Papilio dardanus & 3 & & erratic flight & more tests needed \\
\hline Papilio demodocus & 8 & & moderately active & possibly \\
\hline Papilio lowii & 4 & $2(3)$ & mostly sits & no \\
\hline Papilio nireus & 1 & & & more tests needed \\
\hline Papilio ophidicephalus & 1 & & sit mostly & more tests needed \\
\hline Papilio polytes & 28 & $11(3)$ & $\begin{array}{c}\text { very active } \\
\text { nectars in flight }\end{array}$ & yes \\
\hline Papilio rumanzovia & 2 & & & more tests needed \\
\hline Papilio torquatus & 2 & $2(2)$ & sit mostly & no \\
\hline Parides iphidamas & 10 & & moderately active & possibly \\
\hline
\end{tabular}


Wind tunnel. The wind tunnel used for our temperature study was an open return wind tunnel, which followed the design described by Miller and Roelofs (1978). The original setup had a flat bottom plate and two plexiglass sheets bent around the top, resulting in a half round test section of about $0.89 \mathrm{~m}$ diameter and $2.5 \mathrm{~m}$ length. Our setup was modified to a rectangular configuration and measured about $1.1 \times 1.2$ $\times 2.5 \mathrm{~m}$ (see Fig. 1). Two wooden boxes at the beginning of the test section housed the head of a floor fan and four turbulence dampers of decreasing mesh size to straighten the flow. A variable autotransformer (Variac) enabled the control of the wind speed from 0 to $1.8 \mathrm{~m} / \mathrm{s}$. Six lights were installed at the top of the test section; the four downstream lights had $60 \mathrm{~W}$ incandescent light bulbs and the two upstream lights had $60 \mathrm{~W}$ fluorescent light bulbs, mimicking day light conditions (5500K).

Food source. One of the most crucial components of the experiment is the acceptance of the food source by the butterflies, so that they voluntarily chose to feed in the artificial environment. Offering a known nectar plant of the butterflies was a powerful attractant and the butterflies came to feed at once. A nectar plant, however, is less quantifiable with respect to the resource value to the butterfly (e.g., small differences in smell intensity, nectar amount, or sugar content would influence the butterflies choice) and is therefore not as ideal for experimental purposes. For that reason, several artificial feeders were also tested in the wind tunnel. The most successful model for artificial feeders was achieved by mimicking a natural food source. Nectar was offered from several "artificial flowers" (plastic birthday candle holders that came in various colors) that were mounted on a wooden rod stuck through and suspended by the divider. Cut pieces of Passiflora incarnata leaves were attached to the wooden rod and seemed to attract the butterflies to the nectar source, even when plant pieces were wilted (Fig. 1B). We observed a preference of the butterflies to feed from the blue candle holders over all other colors (yellow, pink and white), but this was not statistically tested. When all colors were offered, most butterflies would only feed from the blue feeders. Replacing the artificial flowers with only blue ones increased the feeding activity substantially. There was no noticeable preference between honey water and lemon/lime Gatorade mix as a food source.

Colored Light Responses. The other explored stimulus was colored light. Color vision of butterflies and the species-dependent preference for certain colors has been shown in previous studies (e.g., Kelber \& Pfaff 1999, Kinoshita et al. 1999). Given this information, four different colored LED lights (yellow, red, blues and purple) and two laser pointers (green and purple) were set up to either shine close to the food source or
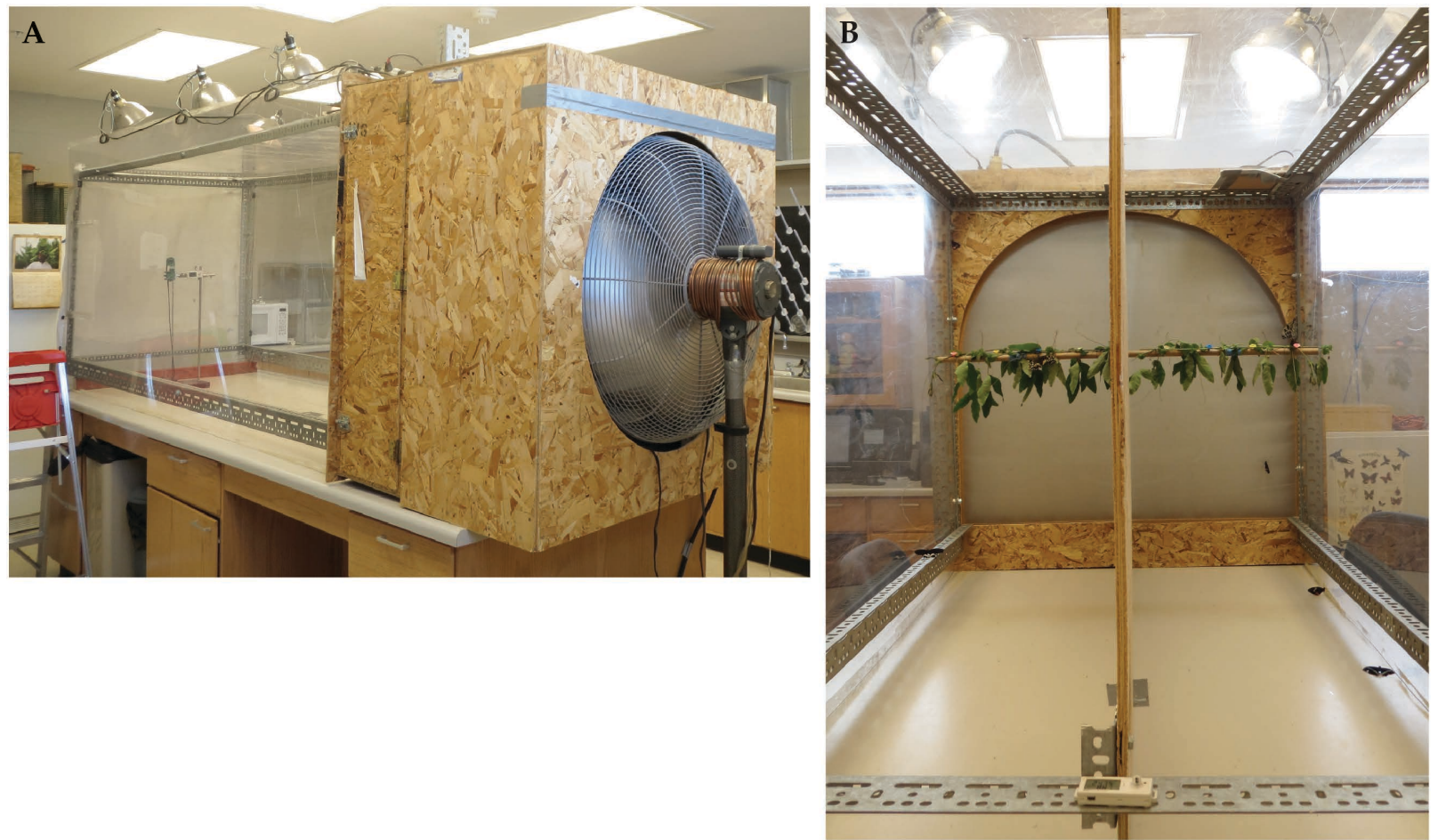

FIG. 1. Wind tunnel setup from upstream $(\mathbf{1 A})$, showing the fan and wooden box with turbulence dampers; inside of the wind tunnel $(\mathbf{1 B})$ with wooded divider and feeding rod with plant materials. Window $(0.3 \times 0.4 \mathrm{~m})$ on side and opening on downstream end allowed researchers to handle butterflies and other materials placed in the wind tunnel. 

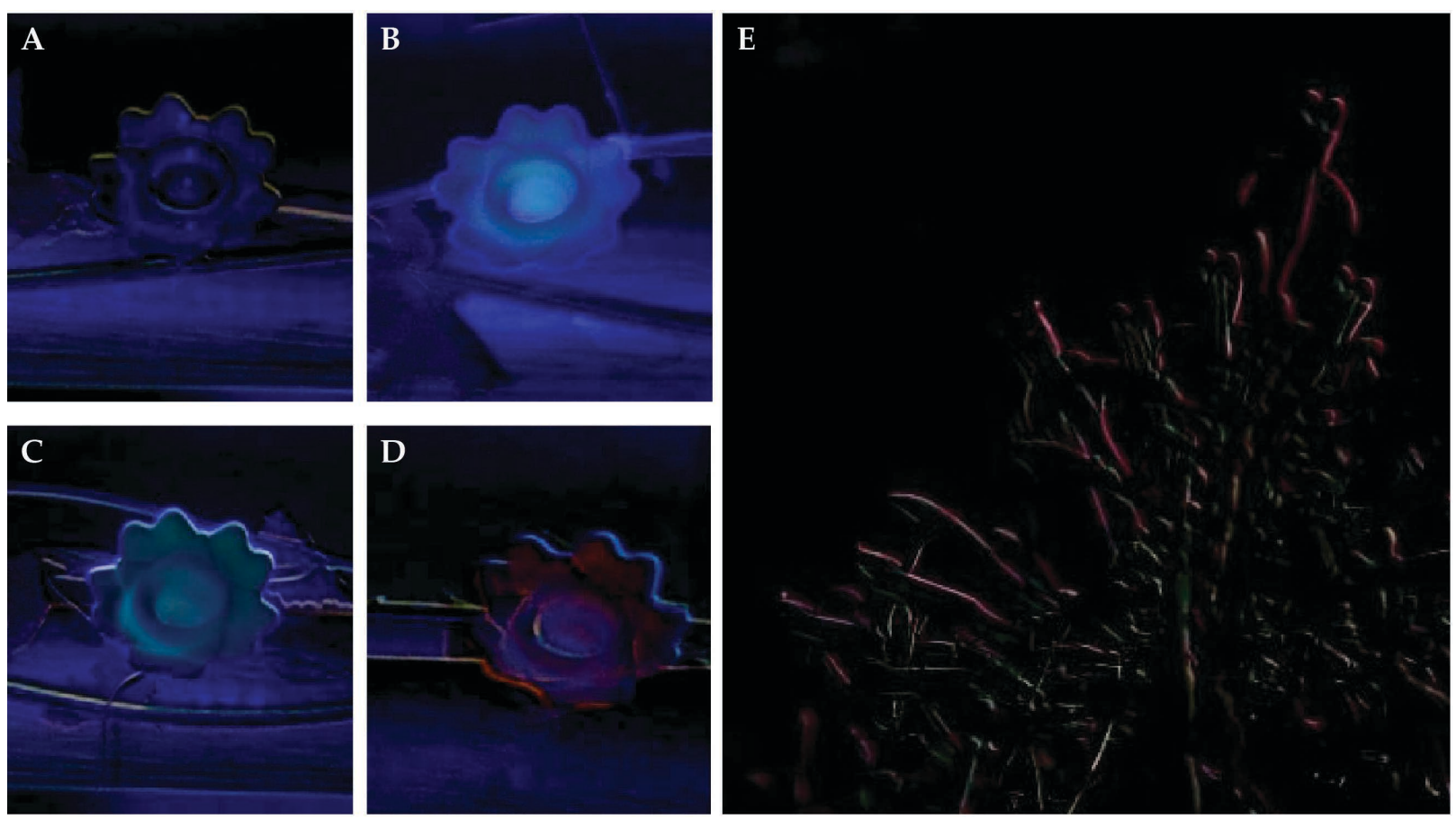

FIG. 2: UV reflectance of the four different birthday candle holders $(\mathbf{2 A})$ yellow, $(\mathbf{2 B})$ pink, $(\mathbf{2 C})$ white and $(\mathbf{2 D})$ blue; UV reflectance of the firespike (Odontonema strictum), a flower that the butterflies frequently nectar from in the butterfly wing (2E).

illuminate the feeder (Eppendorf cup) and the butterflies response was recorded.

UV sensitivity. One of the receptors in butterfly compound eyes is UV sensitive (300nm) (e.g., Menzel 1979, Arikawa et al. 1987, Briscoe \& Chittka 2001). The reaction to purple light and the preference of blue artificial flowers could indicate an increased sensitivity of butterfly eyes to responses in the UV spectrum. To test the UV response of the setup compared to a natural environment, we took UV response pictures of the setup, and specifically the artificial flowers, and compared those to UV response pictures from nectar flowers from the butterfly house at Reiman Gardens. To filter out only the UV component in these pictures, two images were taken with a digital SLR camera (Nikon D90), one under normal light conditions and one with illumination from a UV light source (Ultrafire UV-365nm flashlight). These images and were subtracted from each other using the image processing toolbox in Matlab (R2011b, The MathWorks Inc., Natick, MA).

Temperature sensitivity. For the temperature study, the wind tunnel was divided into two sections (see Fig. 1B). Two space heaters in the back box of the wind tunnel allowed for separate temperature control of the two compartments. Mean temperatures on the cold side were $25.3^{\circ} \mathrm{C}$ and $36.0^{\circ} \mathrm{C}$ on the warm side. This temperature range is within the temperature range that is required for butterflies to achieve optimal wing muscle temperature to sustain flight (e.g., Watt 1968). Warmer temperatures used in this experiment correspond to temperatures that a butterfly might experience over heated roads in the summer in the Midwestern U.S., while lower temperatures correspond to temperatures over prairie or fields within the same season and geographic location. The temperature was randomly varied between trials relative to the two sides to avoid side bias and learning effect of the butterflies. Experiments were conducted for 11 days, which consisted of three test sets where the same individuals were kept in the wind tunnel and their behavior observed for 3-5 consecutive days. A logistic regression was used to analyze the data. The model included species and side as fixed effects, and the butterfly measurement group as a random effect to account for the correlation of consecutive measurement days with the same individuals.

\section{RESULTS}

Colored Light Responses. The LED lights did not inflict a strong response in the butterflies, although a slight attraction could be observed in some species: Heliconius melpomene was attracted to yellow and red, Idea leuconoe to blue and purple and Papilio demodocus to red and purple light. However, all tested species (Battus philenor, Heliconius charitonius, Heliconius melpomene, Idea leuconoe, Papilio dardanus, Papilio demodocus, Papilio polytes and Parides iphidamas) reacted strongly to the purple laser. The reaction ranged 
from turning of the head, antennae movement or wing fluttering when the laser was pointed close to the head. Heliconius charitonius would fly away when the laser pointed close to the butterfly. Idea leuconoe and Papilio polytes would fly or land close to the purple laser spot when pointed to a food source or on the wind tunnel wall.

UV sensitivity. The UV sensitivity test revealed two interesting facts: first, a tape residue located at the wind tunnel wall had attracted the attention of the butterflies during previous observations and showed a high UV reflectance in the pictures; second, the UV response of the artificial flowers differed quite substantially between the colors of the candle holders (Fig. 2). The yellow candle holders showed basically no UV content (Fig. 2A), while both pink and white candle holders had a strong UV reflectance in the blue and green spectrum (Fig. 2B and 2C respectively). Surprisingly, the blue candle holders showed a UV content (Fig. 2D) that showed a similar spectrum to firespike (Odontonema strictum) in the butterfly wing, which is used as a nectar plant for the butterflies at Reiman Gardens (Fig. 2E). It is visible as red color in the subtracted images.

Temperature sensitivity. The temperature study showed that on average all butterfly species examined spent $49.9 \%$ of the time on the cold side, $44.0 \%$ of the time on the warm side and $6.0 \%$ in the back of the wind tunnel section, without temperature division. Species level analyses revealed some species-dependent temperature preferences (Table 2). Two butterfly species (Graphium agamemnon and Junonia coenia) showed no temperature preference, with a probability of choosing the warm side of 0.50 ( $\mathrm{p}=\mathrm{n} . \mathrm{s}$.) and 0.52 ( $\mathrm{p}=\mathrm{n} . \mathrm{s}$.), respectively. Two species had a preference for warm temperature. Papilio lowii had a marginally significant probability of $0.89(\mathrm{p}=0.05)$ and Papilio torquatus had a non-significant probability of 0.60 for choosing the warm side. Conversely, two tested species had a preference for the cold side. Papilio polytes had a significant probability of 0.39 for $(p<0.05)$ for choosing the warm side and
Heliconius spp. had a non-significant probability of 0.43 . Depending on the time of the day and weather condition, there was a strong preference for the right side of the wind tunnel over the left side, regardless of temperature setting, which was taken into account in the general linear model.

\section{DISCUSSION AND CONCLUSION}

The behavioral tests show the importance of both testing different species and training individuals in the wind tunnel prior to experiments. Species dependent behavioral differences and cognitive abilities can affect the activity levels, feeding and flight behavior of the butterflies in wind tunnels. Several tested butterfly species seem to be unsuitable for wind tunnel experiments, because they did not fly in the confined space. This is not surprising, but should be taken into account when designing a wind tunnel experiment and selecting suitable species. Light intensity and food source are important factors to keep butterflies active. Mimicking a natural food source was the most successful strategy to attract butterflies to the offered feeder. Olfactory or visual signals can increase the butterflies' attraction, as long as those additional signals do not introduce unwanted variation into the experiment. Signals in the UV spectrum might have contributed to the acceptance of an artificial feeder. Our experiments highlight the importance of a controlled environment, where only one tested variable can be adjusted. We found that even a slight change in light intensity in the lab environment due to outside weather conditions could bias the outcome of a behavioral study.

This study was designed to examine the underlying reasons for butterfly edge responses by combining aspects of conservation biology and biomechanics. Certain grassland butterfly species react strongly to the presence of habitat edges (e.g., Ries \& Debinski 2001), yet little is know about the physiological reasons for such an edge response. In the controlled environment of a wind tunnel we can test the sensitivity of butterflies to

TABLE 2: Summary of least squares means analysis of temperature dependence for six butterfly species.

\begin{tabular}{lllll}
\hline Species & DF & t Value & Pr $>$ |t| & Mean \\
\hline \hline Graphium agamemnon & 144 & 0.27 & 0.7850 & 0.5248 \\
Heliconius spp. & 144 & -1.51 & 0.1331 & 0.4321 \\
Junonia coenia & 144 & -0.05 & 0.9585 & 0.4967 \\
Papilio lowii & 144 & 1.97 & 0.0513 & 0.8927 \\
Papilio polytes & 144 & -2.08 & 0.0397 & 0.3933 \\
Papilio torquatus & 144 & 0.92 & 0.3594 & 0.6001 \\
\hline
\end{tabular}


isolated parameters that could potentially inflict an edge response, such as ground structure, temperature, light intensity, turbulence, etc.

Although some insects can regulate their body temperature through biochemical processes, butterflies are dependent on ambient temperature (e.g. May 1979). Like all flying insects, butterflies need a certain minimum temperature for their wing muscles to function. They are often observed basking in the sun to increase their thoracic temperature to working conditions. On the other hand, insects can also overheat when ambient temperature increases (e.g. Watt, 1968, May 1979). One could therefore argue that the reason for butterflies to avoid crossing a habitat edge might be related to a temperature difference between different habitats. For example, the temperature over a road on a bright summer day is much higher than the temperature over prairie grassland. To test this hypothesis, we observed whether butterflies had a temperature preference within the temperature range their flight muscles can operate $\left(\sim 25-44^{\circ} \mathrm{C}\right.$, Douglas 1986). In our temperature study, we accounted for side preferences to eliminate the effect of light intensity and weather changes. The side effect also accounted for inactive individuals. If ignored, the stationary behavior of some butterflies could have biased the results if they chose a side and stayed there regardless of the tested variable (in this case, temperature). Our results also highlight the fact that butterfly activity in the wind tunnel depends strongly on the tested species and individual. Many species are not willing to fly in the confined space of a wind tunnel. In such cases, the behavior of a butterfly in the field cannot readily be replicated in a wind tunnel. We were, however, able to show a clear speciesdependent temperature preference for some butterfly species. This is a promising result, demonstrating that our experimental design is suitable to study the sensitivity of different butterfly species to environmental parameters. Although these results, which are mostly based on exotic species, cannot be directly applied to the edge response in native Midwestern butterflies, they provide validation of a technique. Future research will allow us to test these same analytical methods on native grassland-dependent species.

\section{ACKNOWLEDGEMENTS}

The authors thank Dr. Joel Coats for the use of the wind tunnel, Nathan Brockman, Anita Westphal and the Reiman Gardens for the use of their facilities, assistance and helpful discussions during this project and Lendie Follett for statistical advice.

\section{Literature Cited}

Arikawa, K., K. Inokuma, \& E. Eguchi. 1987. Pentachromatic VisualSystem in a Butterfly. Naturwissenschaften 74:297-8.

Briscoe, A. D. \& L. ChittKa. 2001. The evolution of color vision in insects. Annu. Rev. Entomol. 46:471-510.

Brown, K. S. \& A. Freitas. 2000. Atlantic forest butterflies: Indicators for landscape conservation. Biotropica 32:934-56.

Davis, J. D., D. M. Debinski, \& B. J. Danielson. 2007. Local and landscape effects on the butterfly community in fragmented Midwest USA prairie habitats. Landscape Ecol. 22:1341-54.

Douglas, M. M. 1986. The Lives of Butterflies. University of Michigan Press.

Ellis, E. C. \& N. Ramankutty. 2008. Putting people in the map: anthropogenic biomes of the world. Front. Ecol. Environ 6:439-47.

HadDAD, N. M. 1999a. Corridor Use Predicted from Behaviors at Habitat Boundaries. Am. Nat. 153:215-27.

—. 1999b. Corridor and distance effects on interpatch movements a landscape experiment with butterflies. Ecol. Appl. 9:612-22.

HADDAD, N. M. \& K. A. BAUM. 1999. An experimental test of corridor effects on butterfly densities. Ecol. Appl. 9:623-33.

Новвs, R. J. 1993. Can revegetation assist in the conservation of biodiversity in agricultural areas? Pac. Cons. Biol. 1:29-38.

Kelber, A. \& M. Pfaff. 1999. True Colour Vision in the Orchard Butterfly, Papilio aegeus. Naturwissenschaften 86:221-4.

Kinoshita, M., N. Shimada, \& K. ArikaWa. 1999. Colour vision of the foraging swallowtail butterfly Papilio xuthus. J. Exp. Biol. 202:95-102.

Kremen, C. 1992. Assessing the Indicator Properties of Species Assemblages for Natural Areas Monitoring. Ecol. Appl. 2:203-17.

MAY, M. L. 1979. Insect thermoregulation. Annu. Rev. Entomol. 24:313-49.

Menzel, R. 1979. Spectral Sensitivity and Color Vision in Invertebrates. In Autrum H, editor. Handbook of Sensory Physiology. Berlin, Heidelberg: Springer; pp. 503-80.

Miller, J. R. \& W. L. Roelofs. 1978. Sustained-Flight Tunnel for Measuring Insect Responses to Wind-Borne Sex-Pheromones. J Chem. Ecol. 4:187-98.

Pennycuick, C. J. 1968. A wind-tunnel study of gliding flight in the pigeon Columba livia. J. Exp. Biol. 49:509-26.

Ries, L. \& D. M. Debinski. 2001. Butterfly responses to habitat edges in the highly fragmented prairies of Central Iowa. J. Anim. Ecol. 70:840-52.

SAmson, F. \& F. KnOPF. 1994. Prairie conservation in North America. BioScience 44(6):418-421.

Saunders, D. A., R. J. Hobbs, \& C. R. Margules. 1991. Biological consequences of ecosystem fragmentation: a review. Conserv. Biol. 5:18-32

Shepherd, S. \& D. M. Debinski. 2005. Evaluation of isolated and integrated prairie reconstructions as habitat for prairie butterflies. Biol. Cons. 126:51-61.

Swengel, S. R., D. Schlicht, F. Olsen, \& A. B. Swengel. 2011. Declines of prairie butterflies in the Midwestern USA. J. Insect Conserv. 15:327-39.

TUCKER, V. A. 1968. Respiratory exchange and evaporative water loss in the flying budgerigar. J. Exp. Biol. 48:67-87.

VAN DYCK, H. 2011. Changing organisms in rapidly changing anthropogenic landscapes: the significance of the "Umwelt-"concept and functional habitat for animal conservation. Evolutionary Applications 5:144-53.

WATT, W. B. 1968. Adaptive significance of pigment polymorphisms in Colias butterflies. I. Variation of melanin pigment in relation to thermoregulation. Evolution 22: 437-458.

Submitted for publication 17 November 2014; revised and accepted 17 February 2015 